\title{
Produtividade de genótipos de cana de açúcar em resposta à aplicação de calcário em microclima do semiárido brasileiro
}

\author{
Productivity of sugar cane genotypes in response to the limestone application in microclimate of the \\ brazilian semiarid
}
Productividad de genotipos de caña de azúcar en respuesta a la aplicación de caliza en el microclima del semiárido brasileño

Recebido: 03/06/2021 | Revisado: 08/06/2021 | Aceito: 09/06/2021 | Publicado: 23/06/2021

\author{
Marianne Costa de Azevedo \\ ORCID: https://orcid.org/0000-0002-9976-5147 \\ Universidade Federal da Paraíba, Brasil \\ E-mail: mariagro13@gmail.com \\ Edson de Souza Silva \\ ORCID: https://orcid.org/0000-0002-6599-8540 \\ Universidade Federal da Paraíba, Brasil \\ E-mail: eddson_ss@hotmail.com \\ Lucilo Jose de Morais Almeida \\ ORCID: https://orcid.org/0000-0001-9725-7774 \\ Universidade Federal da Paraíba, Brasil \\ E-mail: lucilojose@ hotmail.com \\ Bruno Henrique Braz Rosendo \\ ORCID: https://orcid.org/0000-0002-0923-3148 \\ Universidade Federal da Paraíba, Brasil \\ E-mail: bruno_rosendo500@hotmail.com \\ João Everthon da Silva Ribeiro \\ ORCID: https://orcid.org/0000-0002-1937-0066 \\ Universidade Federal da Paraíba, Brasil \\ E-mail: j.everthon@hotmail.com \\ Djalma Euzébio Simões Neto \\ ORCID: https://orcid.org/0000-0002-8313-0235 \\ Universidade Federal Rural de Pernambuco, Brasil \\ E-mail: desn@oi.com.br \\ Fábio Mielezrski \\ ORCID: https://orcid.org/0000-0003-3409-2479 \\ Universidade Federal da Paraíba, Brasil \\ E-mail:mfabioagro@gmail.com
}

\begin{abstract}
Resumo
Para que o canavial produza satisfatoriamente é necessário que se cultive genótipos de cana de açúcar que seja adaptados as condições edafoclimaticas da região, além disso, também é necessário fazer a correção do solo para que a planta consiga extrair todos os nutrientes necessários ao seu desenvolvimento. Objetivou-se avaliar a produtividade de genótipos de cana de açúcar cultivados com e sem calagem durante os ciclos cana-planta e cana-soca. O delineamento experimental utilizado foi em DBC, com 4 repetições, em esquema fatorial 10 x 2, sendo 10 genótipos de cana de açúcar e dois manejos de calcário (com e sem aplicação). A quantidade de calcário aplicado foi calculada com base na fórmula de elevação de saturação por bases com o resultado da análise de solo, utilizando-se 4,5 tha- 1 de calcário incorporado ao solo na cana planta e 2,8 t ha-1 em superfície na cana soca. Foi avaliado altura de plantas, diâmetro médio do colmo, número de colmos por metro, número de entrenós, ${ }^{\circ}$ Brix, produtividade. Os dados foram submetidos à análise de variância e as médias comparadas entre si pelo teste de Scott-Knott. Os resultados mostram que na cana planta o calcário promoveu o incremento na altura de plantas, diâmetro de colmo, colmos por metro, e produtividade. Na cana soca o calcário influenciou positivamente o número de colmos por metro, e produtividade, sendo o ${ }^{\circ}$ Brix a única variável afetada negativamente. Os genótipos que melhor responderam a calagem foram RB93509, RB002754, RB962962, RB992506 e SP79-1011.
\end{abstract}

Palavras-chave: Calagem; Cana planta; Cana soca; Saccharum officinarum.

\section{Abstract}

For the sugarcane field to produce satisfactorily, it is necessary to cultivate sugarcane genotypes that are adapted to the edaphoclimatic conditions of the region, in addition, it is also necessary to correct the soil so that the plant can 
extract from the soil all the nutrients necessary for its development. The objective of this work was to evaluate the productivity of sugarcane genotypes cultivated with and without liming during the cane-plant and ratoon cane cycles. The experimental design used was in DBC, with 4 replications, in a $10 \times 2$ factorial scheme, with 10 sugarcane genotypes and two lime managements (with and without application). The amount of lime applied was calculated based on the base saturation elevation formula with the result of the soil analysis, using $4.5 \mathrm{t}$ ha- 1 of lime incorporated into the soil in the sugarcane plant and $2.8 \mathrm{t}$ ha- 1 on the surface of the cane. Plant height, average stem diameter, number of stems per meter, number of internodes, ${ }^{\circ}$ Brix, productivity were evaluated. The data were subjected to analysis of variance and the means compared to each other by the Scott-Knott test. The results show that in the cane plant, limestone promoted an increase in plant height, stem diameter, stems per meter, and productivity. In soca cane, limestone positively influenced the number of stems per meter, and productivity, with ${ }^{\circ}$ Brix the only variable negatively affected. The genotypes that responded best to liming were RB93509, RB002754, RB962962, RB992506 and SP79-1011.

Keywords: Liming; Plant cane; Ratoon cane; Saccharum officinarum.

\section{Resumen}

Para que la caña de azúcar se produzca satisfactoriamente, es necesario cultivar genotipos de caña de azúcar que se adapten a las condiciones edafoclimáticas de la región. Además, también es necesario corregir el suelo para que la planta pueda extraer del suelo todos los nutrientes. necesario para su desarrollo. El objetivo de este estudio fue evaluar el productividad de genotipos de caña de azúcar cultivados con y sin encalado durante los ciclos caña-planta y cañasoca. El diseño experimental utilizado fue en DBC, con 4 repeticiones, en un esquema factorial $10 \times 2$, con 10 genotipos de caña de azúcar y dos manejos de cal (con y sin aplicación). La cantidad de cal aplicada se calculó con base en la fórmula de elevación de saturación de base con el resultado del análisis de suelo, utilizando $4.5 \mathrm{t} \mathrm{ha}^{-1} \mathrm{de}$ cal incorporada al suelo en la planta de caña de azúcar y $2.8 \mathrm{t} \mathrm{ha}^{-1}$ en superficie en la soca. . Se evaluó altura de planta, diámetro promedio de tallo, número de tallos por metro, número de entrenudos, ${ }^{\circ}$ Brix, productividad. Los datos se sometieron a análisis de varianza y las medias se compararon mediante la prueba de Scott-Knott. Los resultados muestran que en la planta de caña, la piedra caliza promovió un aumento en la altura de la planta, el diámetro del tallo, los tallos por metro y la productividad. En la caña de azúcar de soca, la piedra caliza influyó positivamente en el número de tallos por metro y la productividad, siendo ${ }^{\circ}$ Brix la única variable que se vio afectada negativamente. Los genotipos que respondieron mejor al encalado fueron RB93509, RB002754, RB962962, RB992506 y SP79-1011.

Palabras clave: Encalado; Caña vegetal; Caña de soca; Saccharum officinarum.

\section{Introdução}

A cana de açúcar (Saccharum officinarum L.) é uma espécie que possui várias variedades, cada uma delas com diferentes características genéticas, exigências em manejo cultura e clima. A cana de açúcar expressa sua máxima produtividade em locais que tenham temperatura entre $22^{\circ}$ e $30^{\circ} \mathrm{C}$, alta intensidade luminosa e uma boa distribuição de chuvas ao longo do ciclo, além de um solo rico em macro e micro nutrientes essenciais à cultura. O manejo cultural e a adaptação da variedade ao clima do local de cultivo são os fatores que mais influenciam no desenvolvimento e na produtividade da cana de açúcar (Meneguetti; Mezaroba; Groff, 2010). Sendo assim é importante que se utilize cultivares indicadas a região e práticas culturais adequadas a cultura e ao local de plantio, promovendo assim aumentos relevantes na produtividade (Capone et al, 2011).

O primeiro procedimento a ser realizado no solo antes da implantação de um canavial é a calagem (Ferraz et al, 2015). Isto porque o $\mathrm{pH}$ do solo afeta a disponibilidade dos nutrientes essenciais e elementos tóxicos no solo, comprometendo o crescimento da cultura e a produtividade. O produto mais utilizado no Brasil para corrigir a acidez do solo é o calcário $\mathrm{Ca}(\mathrm{Mg}) \mathrm{CO}$ 3. Quando aplicado no solo o calcário aumenta o pH e a saturação por bases (V\%), neutraliza o alumínio toxico, e disponibiliza macro e micro nutrientes essenciais as culturas como o $\mathrm{Ca}$ e $\mathrm{Mg}$, promovendo um ambiente mais favorável ao desenvolvimento das culturas (Bambolim et al, 2015).

A cana de açúcar é conhecida como uma cultura que se adapta a solos com ácidos, Rosseto et al (2004) concluíram em seu estudo que o calcário promove benefícios a cana de açúcar quando o solo apresenta baixa fertilidade e pH inferior a 4,4. Porém estudos mais recentes apontam que o aumento do $\mathrm{pH}$ do solo promove aumento na produção da cana de açúcar (Oliveira et al, 2010; Crusciol, 2014; Lima et al 2016).

Apesar do estado da Paraíba apresentar áreas aptas ao cultivo de cana de açúcar, como é o caso das microrregiões do 
Brejo e do Litoral Paraibano (FRANCISCO et al, 2016). Porém a produtividade de cana de açúcar na Paraíba é uma das menores da região Nordeste. Na safra 2019/2020 o estado apresentou uma produtividade média de $54 \mathrm{t} / \mathrm{ha}^{-1}$, cerca de 23 toneladas a menos que a Bahia, estado com maior produtividade da região nesta safra (CONAB 2020).

Devido à baixa produtividade de cana de açúcar na Paraíba, é necessário buscar meios de aumentar a produtividade dos canaviais, usando métodos eficientes e buscando variedades que sejam adaptadas as condições edafoclimaticas da região, com isso objetivou-se avaliar a produtividade de genótipos de cana de açúcar cultivados com e sem calagem durante os ciclos de cana-planta e cana-soca.

\section{Metodologia}

O estudo foi conduzido no município de Areia - PB, na estação experimental Chã de Jardim pertencente a

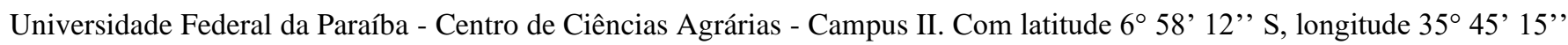
W. A classe de solo predominante do local é o Latossolo vermelho - amarelo (EMBRAPA, 2013). Pela classificação de Koppen, o clima é o tipo Aw' (Peel et al, 2007), o qual se caracteriza como quente e úmido, com chuvas de outono-inverno entre os meses de Fevereiro a Julho. A temperatura média anual de $22^{\circ} \mathrm{C}$, com variações mensais mínimas. Apresenta precipitação média anual de 1400 mm (Ribeiro et al 2018).

Figura 1: Valores de precipitação acumulada durante o mês $(\mathrm{mm})$, insolação total acumulada durante o mês (horas), temperatura média $\left({ }^{\circ} \mathrm{C}\right)$, e umidade relativa (UR\%) durante o período experimental da cana planta e cana soca. Areia, Paraíba, Brasil.

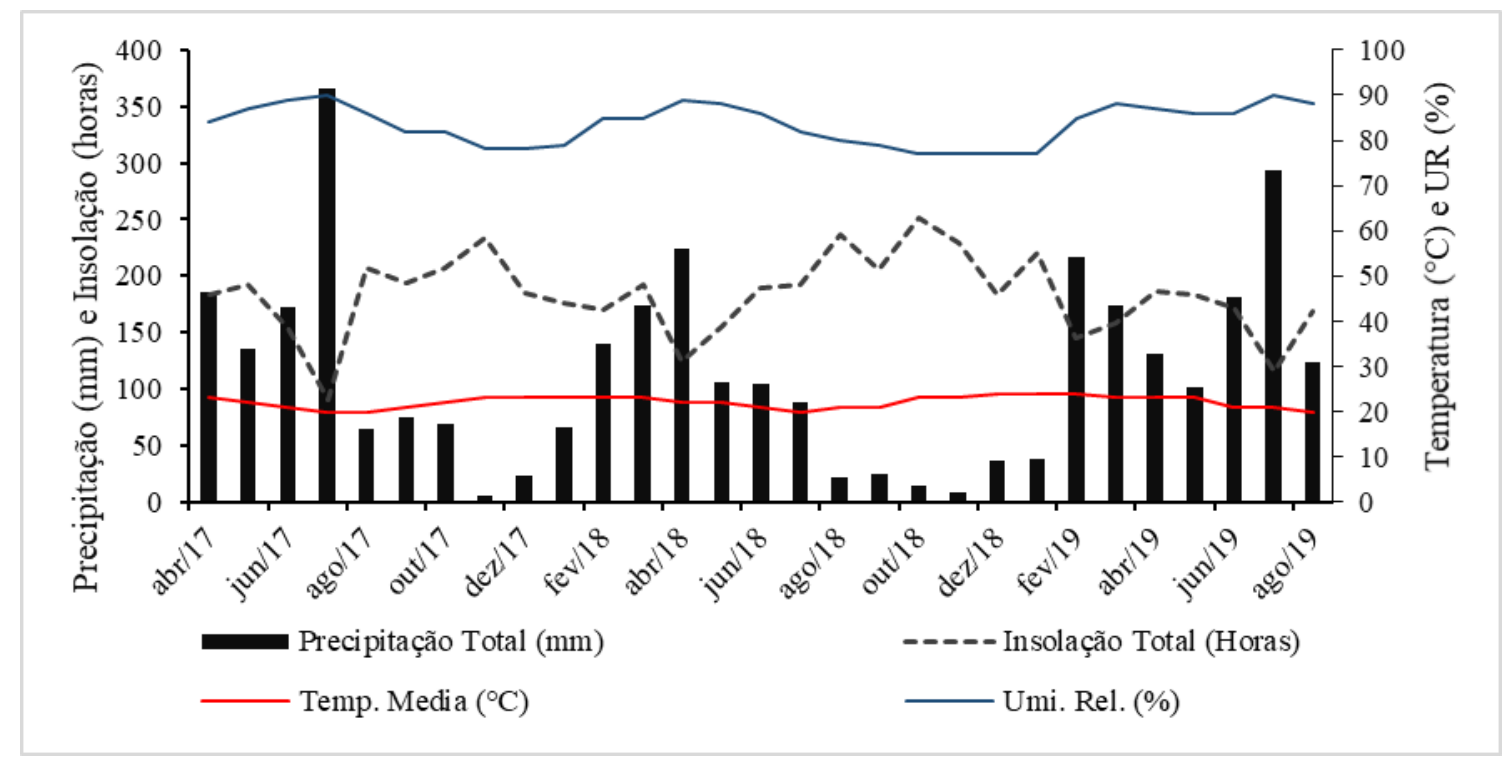

Fonte: INMET (2019)

Utilizou-se o delineamento experimental em blocos casualizados (DBC) com 4 repetições, em esquema fatorial $10 \mathrm{x}$ 2, 10 genótipos de cana de açúcar (RB021754; RB 93 509; RB 00 2754; VAT 212; RB1443; RB 96 2962; RB 86 3129; RB99 2506; SP79 1011; RB 95 154), com dois manejos de calcário (com aplicação e sem aplicação de calcário). Cada parcela mediu 3,6 x 6 m totalizando $21,6 \mathrm{~m}^{2}$ de área útil.

Antes da instalação do experimento foi realizada a coleta de solo (profundidade de $0-20 \mathrm{~cm}$ ) em zigzag em toda a área para a formação de uma amostra composta. A recomendação de calagem e adubação da cana planta foi feita com base na análise de solo da área (Tabela 1). A quantidade de calcário aplicado foi definida de acordo com a fórmula de elevação de 
saturação por bases, chegando a quantidade de 4,5 t/ha $\mathrm{ha}^{-1}$ de calcário dolomitico (PRNT 65\%) aplicado 60 dias antes do plantio da cana de açúcar, que foi distribuído de forma uniforme apenas no local destinado para as parcelas com o tratamento com calcário e depois incorporada ao solo.

Cada parcela foi formada por 4 sulcos com distância de $90 \mathrm{~cm}$ e com 6 metros de comprimento cada. Foram utilizados toletes de cana de açúcar próprios para o plantio de diferentes cultivares, com uniformidade nas suas características fenotípicas. Os sulcos de plantio tinham profundidade aproximada de 20 a $30 \mathrm{~cm}$. O plantio foi realizado de forma manual colocando 16 gemas por metro linear, sendo distribuído os toletes dentro do sulco no padrão pé e ponta, depois da distribuição ocorreu o corte dos toletes em pedaços com aproximadamente $60 \mathrm{~cm}$ dentro do sulco.

Após a colheita da cana planta foi realizada duas novas análises de solo na camada de $0-20 \mathrm{~cm}$, uma coleta apenas com o solo das parcelas com calcário, e outra com solo apenas das parcelas sem calcário. Com base nessas foi calculada a necessidade de calagem e adubação de manutenção (Tabela 1). Foi aplicado 2,8 t/ha ${ }^{-1}$ de calcário dolomítico (PRNT 65\%) apenas nas parcelas do tratamento com calcário, o mesmo foi aplicado nas entrelinhas sem incorporação no solo para não prejudicar a soqueira da cana de açúcar. A quantidade de fertilizantes (Tabela 2) foi a mesma para todas as parcelas do experimento (parcelas com calagem e sem calagem).

Tabela 1: Caracterização química do solo na profundidade de $0-20 \mathrm{~cm}$ na área experimental, Areia, Paraíba, Brasil.

\begin{tabular}{cccc}
\hline & $\begin{array}{c}\text { Antes da implantação da } \\
\text { cana de açúcar }\end{array}$ & $\begin{array}{c}\text { Após o primeiro corte } \\
\text { da cana com calcário }\end{array}$ & $\begin{array}{c}\text { Após o primeiro corte da } \\
\text { cana sem calcário }\end{array}$ \\
\hline $\mathrm{pH}\left(\mathrm{A} \operatorname{gua}_{(1: 2.5)}\right)$ & 4,8 & 6,02 & 5,72 \\
$\mathrm{P}\left(\mathrm{Mg} / \mathrm{dm}^{3}\right)$ & 2,4 & 1,22 & 1,04 \\
$\mathrm{~K}^{+}\left(\mathrm{Mg} / \mathrm{dm}^{3}\right)$ & 28,4 & 28 & 57 \\
$\mathrm{Na}^{+}\left(\mathrm{Cmol} / \mathrm{dm}^{3}\right)$ & 0,05 & 0,11 & 0,14 \\
$\mathrm{H}^{+}+\mathrm{Al}^{+3}\left(\mathrm{Cmol} / \mathrm{dm}^{3}\right)$ & 5,49 & 5,85 & 8,08 \\
$\mathrm{Al}^{+3}\left(\mathrm{Cmol} / \mathrm{dm}^{3}\right)$ & 0,1 & 0 & 0 \\
$\mathrm{Ca}^{+2}\left(\mathrm{Cmol} / \mathrm{dm}^{3}\right)$ & 0,81 & 3,73 & 3,03 \\
$\mathrm{Mg}^{+2}\left(\mathrm{Cmol} / \mathrm{dm}^{3}\right)$ & 0,3 & 2,09 & 1,75 \\
$\mathrm{SB}\left(\mathrm{Cmol} / \mathrm{dm}^{3}\right)$ & 1,23 & 6,21 & 5,5 \\
$\mathrm{CTC}\left(\mathrm{Cmol} / \mathrm{dm}^{3}\right)$ & 6,72 & 12,07 & 13,58 \\
$\mathrm{MO}\left(\mathrm{g} / \mathrm{kg}^{3}\right)$ & 36,72 & 24,27 & 26,83 \\
\hline
\end{tabular}

P, K, Na: Extrator Mehlich 1; SB: Soma de Bases Trocáveis H + Al: Extrator Acetato de Cálcio 0,5 M, pH 7,0; CTC: Capacidade de Troca Catiônica: Al, Ca, Mg: Extrator KCl 1 M; M.O.: Matéria Orgânica - Walkley-Black

Tabela 2: Adubação realizada na cana planta e na cana soca na área experimental, Areia, Paraíba, Brasil.

\begin{tabular}{cccc}
\hline Cana Planta & $\mathrm{N}\left(\mathrm{kg} \mathrm{ha}^{-1}\right)$ & $\mathrm{P}_{2} \mathrm{O}_{5}\left(\mathrm{~kg} \mathrm{ha}^{-1}\right)$ & $\mathrm{K}_{2} \mathrm{O}\left(\mathrm{kg} \mathrm{ha}^{-1}\right)$ \\
\hline Fundação & 30 & 100 & 60 \\
Cobertura (90 DAP) & 70 & 80 & 80 \\
\hline \hline Cana Soca & $\mathrm{N}\left(\mathrm{kg} \mathrm{ha}^{-1}\right)$ & $\mathrm{P}_{2} \mathrm{O}_{5}\left(\mathrm{~kg} \mathrm{ha}^{-1}\right)$ & $\mathrm{K}_{2} \mathrm{O}\left(\mathrm{kg} \mathrm{ha}^{-1}\right)$ \\
\hline Manutenção & 377 & 200 & 180 \\
\hline
\end{tabular}

Fonte: Autores. 
Para a realização das avaliações foram demarcadas cinco plantas nas duas fileiras centrais em cada parcela, sendo realizada as avaliações no final do ciclo da cultura, 15 meses após o plantio na cana planta, e na cana soca 12 meses após o primeiro corte da cana. As avaliações realizadas foram: altura de planta (o comprimento da planta foi mensurado da base até a lígula da folha +1), diâmetro médio do colmo (obtido com base na amostragem dos pontos basal, mediano e apical), número de colmos por metro linear (número de colmos existente nos dois sulcos centrais da parcela, em seguida dividido pelo tamanho dos dois sulcos obtendo assim a quantidade de colmos por metro), número de entrenós (foi contabilizado cada entre nó da base do colmo até o início do palmito), ${ }^{\circ}$ Brix (obtido por meio da média do grau Brix da parte basal e apical das plantas, leitura realizada com um refratômetro), Produtividade - TCH - tonelada por hectare (os colmos industrializáveis dentro da área útil da parcela foram pesados e a partir desse peso foi transformado de quilos por $\mathrm{m} 2$ para toneladas por ha)

Todos os dados coletados foram submetidos à análise de variância e a comparação das médias foi feita pelo teste de Scott-Knott, a 5\% de probabilidade. Na análise estatística foi utilizado o Software AGROESTAT (Barbosa; Maldonado Júnior, 2015).

\section{Resultados e Discussão}

$\mathrm{Na}$ cana planta nenhuma das variáveis avaliadas a interação genótipo x calcário foi significativa (Tabela 3). As variáveis altura de plantas, diâmetro de colmo, número de entrenós, e número de colmos apresentaram diferenças significativas para os fatores genótipos e calcário (Tabela 3). A variável de produtividade (TCH) apresentou diferença significativa apenas para o fator calcário. Já a variável ${ }^{\circ} B r i x$ apresentou diferença estatística apenas para o fator genótipo. Na cana soca as variáveis diâmetro de colmo, número de colmos por metro ${ }^{\circ}$ Brix e TCH apresentaram interação entre genótipos x calagem significativa pelo teste $\mathrm{F}$ todas a $1 \%$ com exceção ao ${ }^{\circ}$ Brix (Tabela 3). As variáveis altura de plantas e número de entrenós apresentou diferença significativa apenas para o fator genótipos (Tabela 3).

Tabela 3: Análise de variância das características fenotípicas e de produtividade (TCH - toneladas de cana por hectare) de diferentes variedades de cana de açúcar com e sem calagem no primeiro e no segundo ano de cultivo. Areia - PB - Brasil.

\begin{tabular}{|c|c|c|c|c|c|c|c|}
\hline \multirow[b]{2}{*}{ Fatores } & \multirow[b]{2}{*}{ GL } & \multicolumn{6}{|c|}{ Quadrado médio Cana planta } \\
\hline & & $\begin{array}{l}\text { Altura de } \\
\text { plantas }\end{array}$ & $\begin{array}{l}\text { Diâmetro de } \\
\text { colmo }\end{array}$ & $\mathrm{N}^{\circ}$ entrenó & $\begin{array}{c}\mathrm{N}^{\mathrm{o}} \\
\text { colmos }\end{array}$ & $\mathrm{TCH}$ & ${ }^{\circ}$ Brix \\
\hline Genótipos (A) & 9 & $0,25 * *$ & $0,33 * *$ & $16,36^{* *}$ & $10,86^{* *}$ & $477,03^{\mathrm{NS}}$ & $9,29 * *$ \\
\hline Calcário (C) & 1 & $14,11^{* *}$ & $0,49 * *$ & $37,89^{* *}$ & $30,83 * *$ & $8254,16^{* *}$ & $1,87^{\mathrm{NS}}$ \\
\hline $\mathrm{A} \times \mathrm{C}$ & 9 & $0,40^{\mathrm{NS}}$ & $0,01^{\mathrm{NS}}$ & $1,69^{\mathrm{NS}}$ & $2,73^{\mathrm{NS}}$ & $316,07^{\mathrm{NS}}$ & $2,53^{\mathrm{NS}}$ \\
\hline C.V. & & 11,8 & 7,69 & 8,52 & 18,45 & 23,23 & 7,99 \\
\hline \multirow[b]{2}{*}{ Fatores } & & \multicolumn{6}{|c|}{ Quadrado médio Cana soca } \\
\hline & GL & $\begin{array}{c}\text { Altura de } \\
\text { plantas }\end{array}$ & $\begin{array}{l}\text { Diâmetro de } \\
\text { colmo }\end{array}$ & $\begin{array}{c}\mathrm{N}^{\circ} \\
\text { entrenó }\end{array}$ & $\begin{array}{c}\mathrm{N}^{\mathrm{o}} \\
\text { colmos }\end{array}$ & $\mathrm{TCH}$ & ${ }^{\circ}$ Brix \\
\hline Genótipos (A) & 9 & $0,21 * *$ & $0,31 * *$ & $24,62^{* * *}$ & $10,26 * *$ & $1465,88^{* *}$ & $5,91^{* *}$ \\
\hline Calcário (C) & 1 & $0,04^{\mathrm{NS}}$ & $0,01^{\mathrm{NS}}$ & $0,06^{\mathrm{NS}}$ & $4,12^{\mathrm{NS}}$ & $8835,00^{* *}$ & $15,31 * *$ \\
\hline$A \times C$ & 9 & $0,02^{\mathrm{NS}}$ & $0,04 * *$ & $1,97^{\mathrm{NS}}$ & $6,22 *$ & $658,75^{* *}$ & $2,65^{*}$ \\
\hline C.V. & & 4,48 & 5,09 & 8,9 & 13,07 & 14,4 & 6,3 \\
\hline
\end{tabular}

Fonte: Autores.

Comparando o pH do solo antes da instalação do experimento com o pH do solo após o corte da cana planta, observase que nas duas situações (solo com calcário e solo sem calcário) houve o aumento do $\mathrm{pH}$ (Tabela 1). Isto se atribui a dois 
fatores principais, o efeito neutralizador e residual do calcário, no caso do das parcelas onde foi feita a calagem, e a adubação potássica, uma vez que o potássio é uma base e o pH do solo tem relação com a saturação de bases do mesmo (BAMBOLIM et al 2015).

A Tabela 4 apresenta a altura de plantas de cana planta cultivadas com e sem calcário. Observa-se que não houve diferença significativa entre a alturas de plantas dos genótipos cultivados com e sem calcário. O genótipo RB962962 apresentou ganho significativo de $30 \mathrm{~cm}$ na altura de plantas com o uso da calagem no solo, os demais genótipos não tiveram a sua altura de plantas afetada pela calagem.

Já na cana soca (Tabela 4) o calcário não afetou a altura de plantas de nenhum dos genótipos. Os genótipos RB1443 (2,7m), RB962962 (2,5m), e RB992506 (2,5m) tiveram maior altura de plantas quando comparados aos demais genótipos quando cultivados com calcário. Entre os genótipos que apresentaram maior altura de plantas sem calcário foram estão RB1443 (2,6m), RB962962 (2,6m), RB002752 (2,5m), RB992506 (2,5m) e RB93509 (2,4m).

Na cana planta os genótipos com maior diâmetro de colmo (Tabela 4) foram RB002754 (2,7cm), RB021754 (2,5cm), VAT90-212 (2,4cm), SP79-1011 (2,4cm), RB863129 (2,4cm) quando cultivados com calcário. Quando cultivados sem calcário os genótipos com maior diâmetro de colmo foram RB002754 (2,6cm) e RB021754 (2,4cm). O uso do calcário proporcionou um acréscimo de 0,3 cm no diâmetro de colmo dos genótipos VAT90-212 e RB1443.

Na cana soca o genótipo RB002754 apresentou o maior diâmetro de colmo (Tabela 4) apresentando 2,85 cm quando cultivado com calcário e $2,96 \mathrm{~cm}$ quando cultivado sem o calcário, porém a utilização de calcário não afetou o diâmetro de colmo deste genótipo. O genótipo RB021754 teve seu diâmetro de colmo aumentado em razão da utilização do calcário apresentando 0,31 cm a mais quando cultivado com calcário. Fato inverso ocorreu com o genótipo RB962962, o diâmetro de colmo das plantas cultivadas sem o calcário foi maior que o diâmetro das plantas cultivados com calcário. 
Tabela 4: Altura de plantas e diâmetro de colmo de diferentes genótipos de cana de açúcar cultivados com (CC) e sem calcário (SC) na cana planta e cana soca. Letras maiúsculas nas colunas comparam os diferentes genótipos dentro do manejo com calcário. Letras minúsculas nas linhas compara o efeito do calcário dentro de cada genótipo. Medias seguidas pela mesma letra não diferem entre si pelo teste de Scott\&Knott a 5\% de probabilidade.

\begin{tabular}{|c|c|c|c|c|c|}
\hline \multicolumn{6}{|c|}{ CANA-PLANTA } \\
\hline \multirow{2}{*}{ Genótipos } & \multicolumn{2}{|c|}{ Altura de plantas $(\mathrm{m})$} & \multicolumn{3}{|c|}{ Diâmetro de colmo $(\mathrm{cm})$} \\
\hline & $\mathrm{CC}$ & $\mathrm{SC}$ & $\mathrm{CC}$ & \multicolumn{2}{|r|}{$\mathrm{SC}$} \\
\hline RB021754 & 2,5 Aa & $2,4 \mathrm{Aa}$ & $2,5 \mathrm{Aa}$ & 2,4 & $\mathrm{Aa}$ \\
\hline RB93509 & $2,5 \mathrm{Aa}$ & $2,3 \mathrm{Aa}$ & $2,3 \mathrm{Aa}$ & 2,2 & $\mathrm{Ba}$ \\
\hline RB002754 & $2,7 \mathrm{Aa}$ & $2,6 \mathrm{Aa}$ & $2,7 \mathrm{Aa}$ & 2,6 & $\mathrm{Aa}$ \\
\hline VAT90-212 & $2,6 \mathrm{Aa}$ & $2,2 \mathrm{Aa}$ & $2,4 \mathrm{Aa}$ & 2,1 & $\mathrm{Bb}$ \\
\hline RB 1443 & $2,7 \mathrm{Aa}$ & 2,4 Аa & $2,1 \mathrm{Ba}$ & 1,8 & $\mathrm{Cb}$ \\
\hline RB962962 & 3 Аа & $2,6 \mathrm{Ab}$ & $2,2 \mathrm{Ba}$ & 2,1 & $\mathrm{Ba}$ \\
\hline RB863129 & $2,6 \mathrm{Aa}$ & 2,3 Аа & $2,3 \mathrm{Aa}$ & 2,2 & $\mathrm{Ba}$ \\
\hline RB992506 & 2,7 Аa & $2,6 \mathrm{Aa}$ & $2 \mathrm{Ba}$ & 1,9 & $\mathrm{Ca}$ \\
\hline SP79-1011 & 2,4 Аа & 2,1 Аа & $2,4 \mathrm{Aa}$ & 2,2 & $\mathrm{Ba}$ \\
\hline RB951541 & $2,6 \mathrm{Aa}$ & $2,3 \mathrm{Aa}$ & $2,2 \mathrm{Ba}$ & 2,1 & $\mathrm{Ba}$ \\
\hline \multicolumn{6}{|c|}{ CANA-SOCA } \\
\hline \multirow{2}{*}{ Genótipos } & \multicolumn{2}{|c|}{ Altura de plantas (m) } & \multicolumn{3}{|c|}{ Diâmetro de colmo $(\mathrm{cm})$} \\
\hline & $\mathrm{CC}$ & $\mathrm{SC}$ & $\mathrm{CC}$ & & $\mathrm{SC}$ \\
\hline RB021754 & $2,3 \mathrm{Ba}$ & $2,3 \mathrm{Ba}$ & $2,6 \mathrm{Ba}$ & 2,3 & $\mathrm{Db}$ \\
\hline RB93509 & $2,3 \mathrm{Ba}$ & $2,4 \mathrm{Aa}$ & $2,5 \mathrm{Ca}$ & 2,5 & $\mathrm{Ca}$ \\
\hline RB002754 & $2,3 \mathrm{Ba}$ & $2,5 \mathrm{Aa}$ & 2,9 Аа & 3 & $\mathrm{Aa}$ \\
\hline VAT90-212 & $2,1 \mathrm{Ba}$ & $2,3 \mathrm{Ba}$ & $2,4 \mathrm{Ca}$ & 2,5 & $\mathrm{Ca}$ \\
\hline RB1443 & $2,7 \mathrm{Aa}$ & $2,6 \mathrm{Aa}$ & $2,2 \mathrm{Da}$ & 2,2 & $\mathrm{Da}$ \\
\hline RB962962 & $2,5 \mathrm{Aa}$ & $2,6 \mathrm{Aa}$ & $2,3 \mathrm{Db}$ & 2,6 & $\mathrm{Ba}$ \\
\hline RB863129 & $2,3 \mathrm{Ba}$ & $2,2 \mathrm{Ba}$ & $2,7 \mathrm{Ba}$ & 2,6 & $\mathrm{Ba}$ \\
\hline RB992506 & $2,5 \mathrm{Aa}$ & $2,5 \mathrm{Aa}$ & $2,3 \mathrm{Da}$ & 2,4 & $\mathrm{Ca}$ \\
\hline SP79-1011 & $2,1 \mathrm{Ba}$ & $2,1 \mathrm{Ba}$ & $2,5 \mathrm{Ca}$ & 2,4 & $\mathrm{Ca}$ \\
\hline RB951541 & $2,2 \mathrm{Ba}$ & $2,2 \mathrm{Ba}$ & $2,3 \mathrm{Da}$ & 2,2 & $\mathrm{Da}$ \\
\hline
\end{tabular}

Fonte: Autores.

Apenas o genótipo RB962962 apresentou o diâmetro de colmo maior quando cultivado sem calcário, e tal fato foi observado apenas na cana soca. A provável ocorrência disto pode ser associada ao fato de que o diâmetro de colmo tente a ser maior em condições de estresse como foi observado por Oliveira et al (2016). Os resultados encontrados nesse estudo (altura de plantas e diâmetro de colmo) não corroboram com os dados encontrados por Vieceli et al (2020), de acordo com os autores a calagem não afeta a altura e o diâmetro de colmo da cana de açúcar. Vale salientar que os autores avaliaram apenas um genótipo de cana de açúcar e três dosagens de calcário isolado, duas dosagens de gesso isolado e uma dosagem de calcário mais gesso, além da testemunha, sem o uso de calcário e gesso.

Conforme a Tabela 5 na cana planta apenas os genótipos RB951541 e RB962962 apresentaram maior no de entrenós quando cultivados com calagem, apresentando 26 e 25 entrenós por colmo respectivamente. Já os genótipos que se destacaram com o maior $\mathrm{n}^{\circ}$ de entrenós quando cultivados sem calcário foram RB951541 com 24 entrenós, RB002754 também com 24 
entrenós e o RB962962 com 23 entrenós. Nenhum genótipo teve o seu nº de entrenós afetado pelo uso do calcário.

Na cana soca (Tabela 5) observa-se que nenhum genótipo teve o seu número de entrenós por colmo influenciado pela calagem, semelhante ao que ocorreu na cana planta. Tanto na cana soca cultivada com calcário como na cana cultivada sem calcário o único genótipo que apresentou no de entrenós superior aos demais foi o RB1443 com 21 entrenós para ambos.

Na variável número de colmos por metro da cana planta (Tabela 5) o calcário promoveu o aumento significativo de colmos por metro apenas para o genótipo RB992506, que apresentou um ganho de três colmos por metro quando comparado com o mesmo genótipo cultivado sem calcário. Apenas os genótipos RB021754, RB002754 e RB951541 apresentaram nº de colme inferior aos demais genótipos quando cultivados com calagem. Já quando os genótipos foram cultivados sem calagem apenas o RB93509 e RB1443 tiveram o ${ }^{\circ}$ de colmos por metro superior aos demais genótipos.

Verifica-se na Tabela 5 que os genótipos RB93509 e RB955141 quando cultivados com calcário apresentaram n ${ }^{\circ}$ superior de colmos por metro em relação a esses mesmos genótipos cultivados sem calcário. Dentre os genótipos cultivados com calcário os que apresentaram um maior número de colmos por m foram RB021754, RB93509, RB992506 e RB951541. Já os genótipos cultivados sem calcário que apresentaram maior número de colmos por m foi RB002754, RB1443, RB863129, RB992506, SP791011 e RB951541. 
Tabela 5: Numero de entrenós e números de colmos por metro de diferentes genótipos de cana de açúcar cultivados com (CC) e sem calcário (SC) no primeiro e segundo ano de cultivo. Letras maiúsculas comparam os genótipos dentro de cada manejo do solo (comparação dentro da coluna) letras minúsculas comparam o manejo do solo dentro de cada genótipo (comparação dentro das linhas). Medias seguidas pela mesma letra não diferem entre si pelo teste de Scott\&Knott a 5\% de probabilidade.

\begin{tabular}{|c|c|c|c|c|c|c|}
\hline \multicolumn{7}{|c|}{ CANA-PLANTA } \\
\hline \multirow{2}{*}{ Genótipos } & \multicolumn{3}{|c|}{$\mathrm{N}^{\circ}$ de entrenós } & \multicolumn{3}{|c|}{ Colmos por metro } \\
\hline & \multicolumn{2}{|c|}{$\mathrm{CC}$} & $\mathrm{SC}$ & $\mathrm{CC}$ & \multicolumn{2}{|l|}{$\mathrm{SC}$} \\
\hline RB021754 & 22,8 & $\mathrm{Ba}$ & $21,4 \mathrm{Ba}$ & $7 \mathrm{Ba}$ & $8,3 \mathrm{~B}$ & $\mathrm{Ba}$ \\
\hline RB93509 & 22,6 & $\mathrm{Ba}$ & $20,6 \mathrm{Ba}$ & $11,3 \mathrm{Aa}$ & $11,3 \mathrm{~A}$ & $\mathrm{Aa}$ \\
\hline RB002754 & 24 & $\mathrm{Ba}$ & 24,1 Aa & $9 \mathrm{Ba}$ & $7,5 \mathrm{~B}$ & $\mathrm{Ba}$ \\
\hline VAT90-212 & 23,1 & $\mathrm{Ba}$ & $21,4 \mathrm{Ba}$ & $10,3 \mathrm{Aa}$ & $8,3 \mathrm{~B}$ & $\mathrm{Ba}$ \\
\hline RB1443 & 23,3 & $\mathrm{Ba}$ & $20,6 \mathrm{Ba}$ & 11,3 Aa & $10,8 \mathrm{~A}$ & $\mathrm{Aa}$ \\
\hline RB962962 & 26 & $\mathrm{Aa}$ & $23,8 \mathrm{Aa}$ & $10,3 \mathrm{Aa}$ & $8,5 \mathrm{~B}$ & $\mathrm{Ba}$ \\
\hline RB863129 & 21,5 & $\mathrm{Ba}$ & $20,5 \mathrm{Ba}$ & $10,3 \mathrm{Aa}$ & $8,7 \mathrm{~B}$ & $\mathrm{Ba}$ \\
\hline RB992506 & 22,2 & $\mathrm{Ba}$ & $22,3 \mathrm{Ba}$ & $11 \mathrm{Aa}$ & $8,3 \mathrm{~B}$ & $\mathrm{Bb}$ \\
\hline SP79-1011 & 22,8 & $\mathrm{Ba}$ & $21,5 \mathrm{Ba}$ & $10,8 \mathrm{Aa}$ & $9,3 \mathrm{~B}$ & $\mathrm{Ba}$ \\
\hline RB951541 & 26 & $\mathrm{Aa}$ & $24,3 \quad \mathrm{Aa}$ & $9,3 \mathrm{Ba}$ & $7,3 \mathrm{~B}$ & $\mathrm{Ba}$ \\
\hline \multicolumn{7}{|c|}{ CANA-SOCA } \\
\hline \multirow{2}{*}{ Genótipos } & \multicolumn{3}{|c|}{$\mathrm{N}^{\mathrm{o}}$ de entrenós } & \multicolumn{3}{|c|}{ Colmos por metro } \\
\hline & \multicolumn{2}{|c|}{$\mathrm{CC}$} & $\mathrm{SC}$ & $\mathrm{CC}$ & \multicolumn{2}{|l|}{$\mathrm{SC}$} \\
\hline RB021754 & 16,2 & $\mathrm{Ba}$ & $15 \mathrm{Ba}$ & $13 \mathrm{Aa}$ & $10,4 \mathrm{~B}$ & $\mathrm{Ba}$ \\
\hline RB93509 & 16,7 & $\mathrm{Ba}$ & $16,6 \mathrm{Ba}$ & 14,3 Aa & $11,8 \quad \mathrm{~A}$ & $\mathrm{Ab}$ \\
\hline RB002754 & 16,2 & $\mathrm{Ba}$ & $17,7 \quad \mathrm{Ba}$ & $9,6 \mathrm{Ba}$ & $9,6 \mathrm{~B}$ & $\mathrm{Ba}$ \\
\hline VAT90-212 & 15,4 & $\mathrm{Ba}$ & $16,9 \mathrm{Ba}$ & $11 \mathrm{Ba}$ & $10,5 \mathrm{~B}$ & $\mathrm{Ba}$ \\
\hline RB1443 & 22 & $\mathrm{Aa}$ & 21,3 Aa & $10,6 \mathrm{Ba}$ & $12,1 \quad \mathrm{~A}$ & $\mathrm{Aa}$ \\
\hline RB962962 & 17,9 & $\mathrm{Ba}$ & $18,4 \mathrm{Ba}$ & $11,4 \quad \mathrm{Ba}$ & $11,1 \quad \mathrm{~B}$ & $\mathrm{Ba}$ \\
\hline RB863129 & 17,2 & $\mathrm{Ba}$ & $16,4 \mathrm{Ba}$ & $10,7 \mathrm{Ba}$ & $12,5 \mathrm{~A}$ & Aa \\
\hline RB992506 & 17,1 & $\mathrm{Ba}$ & $17,1 \quad \mathrm{Ba}$ & $13,1 \mathrm{Aa}$ & $12,8 \quad \mathrm{~A}$ & $\mathrm{Aa}$ \\
\hline SP79-1011 & 15,9 & $\mathrm{Ba}$ & $15,3 \quad \mathrm{Ba}$ & $11 \mathrm{Ba}$ & $12,4 \quad \mathrm{~A}$ & $\mathrm{Aa}$ \\
\hline RB951541 & 18,4 & $\mathrm{Ba}$ & $17,4 \mathrm{Ba}$ & 14,9 Аa & $11,9 \quad \mathrm{~A}$ & $\mathrm{Ab}$ \\
\hline
\end{tabular}

Fonte: Autores.

Os componentes de rendimento que mais afetam a produtividade são o diâmetro de colmo, altura de colmo e número de colmos por metro, sendo o principal deles o número de colmos por metro. Devido a isso qualquer aumento em um desses componentes causaria aumento consequente da produtividade (Espósito et al 2012).

Observa-se na Figura 2A que o ${ }^{\circ}$ Brix de todos os genótipos são superiores a 16, tanto no tratamento com calcário, quanto no tratamento sem calcário. Nenhum dos genótipos teve o seu ${ }^{\circ}$ Brix afetado em decorrência do uso do calcário. Quando cultivados com calcário os genótipos RB992606, SP79-1011 e RB021754 apresentaram os maiores valores de Brix, acima de 20. Já quando cultivados sem calcário apenas os RB93509, RB863129, RB962962 se mostraram inferiores as demais com valores abaixo de 18.

Na Figura 2B observa-se a influência do calcário no teor de ${ }^{\circ}$ Brix da cana soca. Os genótipos RB021754, RB93509, RB002754, RB 962962 e RB863129 obtiveram maior teor de açucares quando cultivados sem calcário. O valor máximo de ${ }^{\circ}$ Brix encontrado nos genótipos cultivados com calcário foi 18,1 no genótipo RB992506, esse valor é igual estatisticamente aos valores dos genótipos RB1443, SP791011 e RB951541. Entre os genótipos cultivados sem calcário destacam-se apenas o 
RB1443 $(19,12)$ e o RB863129 (16,38) apresentando Brix superior à dos demais genótipos.

Figura 2: ${ }^{\circ}$ Brix de diferentes genótipos de cana de açúcar cultivados com (CC) e sem calcário (SC) no primeiro ano (A) de cultivo e segundo ano de cultivo (B). Letras maiúsculas comparam os diferentes genótipos dentro do manejo com calcário. Letras maiúsculas comparam os diferentes genótipos dentro do manejo com calcário. Letras minúsculas compara o efeito do calcário dentro de cada genótipo. Medias seguidas pela mesma letra não diferem entre si pelo teste de Scott\&Knott a $1 \%$ de probabilidade.

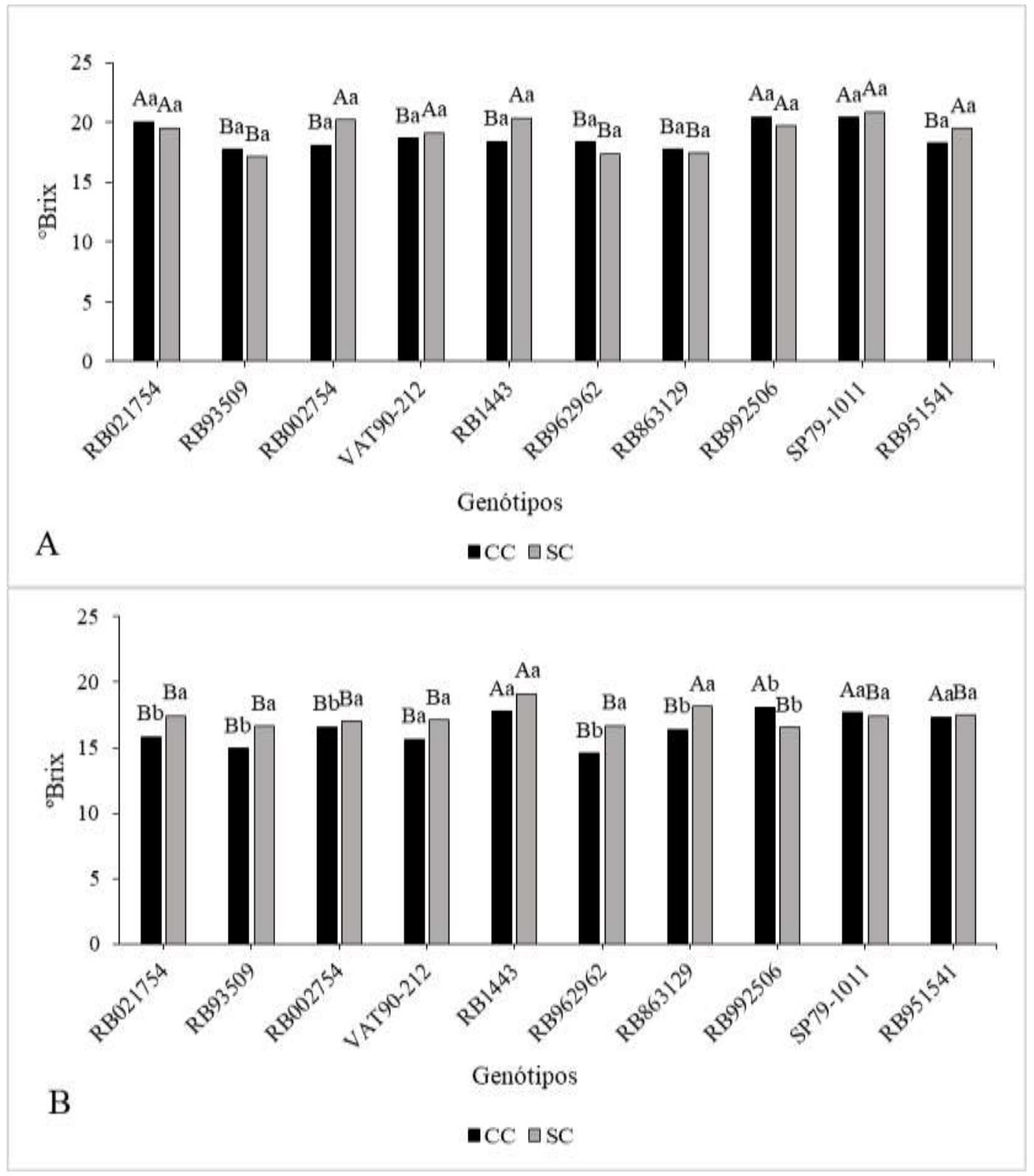

Fonte: Autores.

As altas precipitações pluviométricas próximas a colheita contribuíram para os baixos teores de ${ }^{\circ}$ Brix da cana soca. Os resultados de ${ }^{\circ}$ Brix encontrados no presente trabalho corroboram com os resultados encontrados por outros autores que concluíram que o ${ }^{\circ}$ Brix da cana de açúcar não responde positivamente a aplicação silicato de cálcio mais gesso (Crusciol et al 2014), silicato mais calcário (Prado et al 2001) e também a aplicação de gesso (Carvalho et al 2013). Uma possível explicação para tal fato e que os vegetais quando cultivados em locais com condições estressantes tentem a reduzir o seu ciclo e aumentar 
o armazenamento de açucares, já quando cultivados em locais livre de qualquer condição de estresse os vegetais aumentam o seu ciclo, pois utilizam os carboidratos produzidos são usados para aumentar o crescimento vegetativo, e acabam armazenando menos açucares. Segundo a Ridesa, 2010 os genótipos RB962962 e RB93509 possuem alto teor de sacarose, no entanto apresentaram baixo ${ }^{\circ}$ Brix (abaixo de 19) como pode ser observado na Figura 2.

A produtividade dos genótipos na cana planta não possuem diferenças significativas, tanto no cultivo com calcário quanto no cultivo sem calcário (Figura 3A). Os genótipos RB002754, VAT90-212 e SP79-1011 tiveram sua produtividade

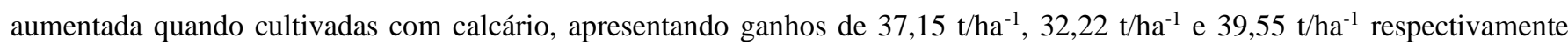
(Figura 3A).

Na Figura 3B observa-se que o calcário foi eficiente em aumentar a produtividade dos genótipos RB93509 com o acréscimo de 47,3 t/ha ${ }^{-1}$, RB002754 com o aumento de 42,7 t/ha ${ }^{-1}$, RB962962 com o acréscimo de 23,33 t/ha ${ }^{-1}$, RB992506 com o acréscimo de 21,04 t/ha-1, e o SP791011 com o acréscimo de 39,58 t/ha ${ }^{-1}$. O único genótipo cultivado com calcário que deferiu estatisticamente dos demais e obteve maior produtividade foi o RB002754. Este mesmo genótipo se destacou na produtividade da cana soca cultivada sem calcário sendo igual estatisticamente com os genótipos RB021754 e VAT90-212 com 108,7 t/ha ${ }^{-1}$; 101,03 t/ha ${ }^{-1}$ e 93,54 t/ha ${ }^{-1}$ respectivamente. 
Figura 3: Toneladas de cana por hectare (TCH) de diferentes genótipos de cana de açúcar cultivados com (CC) e sem calcário (SC) no primeiro ano (A) de cultivo e segundo ano de cultivo (B). Letras maiúsculas comparam os diferentes genótipos dentro do manejo de calagem. Letras minúsculas compara o efeito do manejo de calagem dentro de cada genótipo. Medias seguidas pela mesma letra não diferem entre si pelo teste de Scott\&Knott a $1 \%$ de probabilidade.

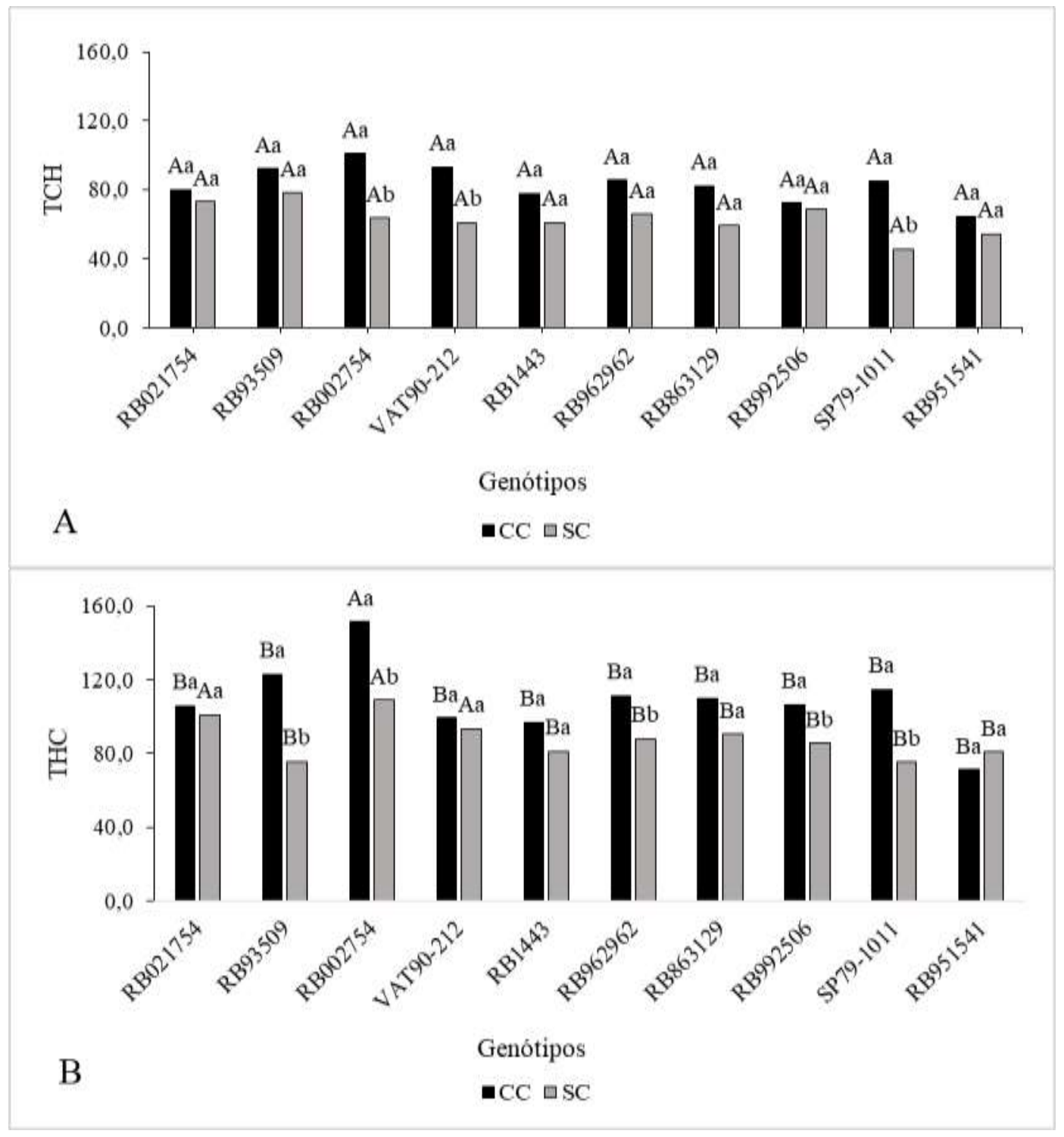

Fonte: Autores.

Tradicionalmente o estado da Paraíba apresenta produtividades media abaixo de $60 \mathrm{TCH}$, como foi observado nas safras 2017/2018 com 48,7 t/ha-1, 2018/2019 com 45,7 t/ha-1 e 2019/2020 54,8 t/ha- ${ }^{-1}$ A cultivar que apresentou a menor produtividade durante os dois anos de estudo foi a SP79-1011 quando cultivada sem calcário no primeiro ano de cultivo apresentando apenas 45,7 t/ha-1 ${ }^{-1}$ os demais genótipos apresentaram produtividades superiores a média do estado, mesmo quando cultivados sem calcário. Uma possível explicação para tal fato é que os produtores de cana não costumam realizar análises fertilidade de solo entre as safras, e a adubação e a calagem acabam sendo insuficiente para as reais necessidades da cultura.

As variedades SP79-1011 e RB863129 quando manejadas com irrigação plena podem apresentar produtividade superior a encontrada no presente trabalho, chegando a 155 e $181 \mathrm{t} / \mathrm{ha}^{-1}$ respectivamente, como é apresentado por Oliveira et al 
2010. As variedades RB962962 e RB93509 possuem alta produtividade segundo a Ridesa, 2010. No presente estudo estes genótipos apresentaram produtividade inferior estatisticamente aos demais genótipos.

A calagem promoveu o aumento da produtividade em cinco dos dez genótipos utilizados no estudo, esses dados corroboram com os resultados encontrados por Crusciol, 2014 e Lima et al 2016 que observaram o aumento do número de colmos por metro e da produtividade da cana de açúcar quando o pH do solo era elevado através de corretivos, ambos autores atribuíram esse fato a redução do alumínio toxico do e ao aumento da disponibilidade de nutrientes como $\mathrm{P}$ e $\mathrm{K}$ principalmente em maior profundidades. Outros materiais alternativos como a carapaça do mexilhão dourado devem ser testados na cana de açúcar, uma vez que, o uso da carapaça do mexilhão dourado moída ou em pedaços possuem eficiência em fornecer cálcio ao solo e neutralizar o alumínio tóxico, podendo substituir o calcário (MALTONI et al, 2020).

O calcário quando aplicado apenas na superfície tem efeito duradouro, chegando a mais de 24 meses, porém esses efeitos não são uniformes no perfil do solo, sendo assim a aplicação do calcário em superfície não consegue elevar a saturação por base em profundidade a níveis desejados para as culturas (GONÇALVES et al, 2011), devido a isso, o uso de calcários com PRNT mais baixo incorporados ao solo, como o calcário utilizado neste estudo, podem ser uma alternativa para implantação da cana de açúcar e para cultivos em sistema de plantio direto, uma vez que calcários com PRNT mais baixos possuem elevado efeito residual do solo, mantendo a fertilidade do mesmo e aumentando o período entre aplicações sucessivas (RATKE et al 2018).

\section{Conclusão}

O genótipo RB002754 apresentou maior adaptação ao microclima do brejo paraibano;

O calcário promove o aumento nos componentes de rendimento da cana de açúcar, e consequentemente aumentos na produtividade, sobretudo na cana soca.

Os genótipos que melhor responderam a calagem foram RB93509, RB002754, RB962962, RB992506, SP79-1011

$\mathrm{O}{ }^{\circ} \mathrm{Brix}$ foi a única variável afetada negativamente pela calagem do solo.

Os resultados obtidos nesse experimento estimulam a realização de novas pesquisas com outros genótipos de cana de açúcar e outros corretivos de acidez do solo.

\section{Referências}

Bambolim, A., Caione, G., Souza, N. F., Junior, G. D. F. S., \& Ferbonink, G. F. (2015). Calcário líquido e calcário convencional na correção da acidez do solo. JOURNAL OF NEOTROPICAL AGRICULTURE, 2(3), 34-38.

Barbosa, J. C., \& Maldonado Junior, W. (2015). AgroEstat: sistema para análises estatísticas de ensaios agronômicos. Jaboticabal, FCAV/UNESP. 396p.

Carvalho, J. M., Andreotti, M., Buzetti, S., \& Carvalho, M. D. P. (2013). Produtividade de cana soca sem queima em função do uso de gesso e vinhaça. Pesquisa Agropecuária Tropical, 43(1), 1-9.

CONAB. (2019). Acompanhamento da safra brasileira de cana-de-açúcar. (2a ed.), (V. 6 - Safra 2019/20).

Crusciol, C. A. C., Foltran, R., Rossato, O. B., McCray, J. M., \& Rossetto, R. (2014). Effects of surface application of calcium-magnesium silicate and gypsum on soil fertility and sugarcane yield. Revista Brasileira de Ciência do Solo, 38(6), 1843-1854.

EMBRAPA Solos. (2013). Sistema brasileiro de classificação de solos. Centro Nacional de Pesquisa de Solos. 3 , 342.

Espósito, D. P., Peternelli, L. A., de Paula, T. O. M., \& Barbosa, M. H. P. (2012). Path analysis using phenotypic and genoty pic values for yield components in the selection of sugarcane families. Ciência Rural, 42 (1), 38-44.

Francisco, P. R. M., Guimarães, C. L., \& Falle, L. M. (2016). Aptidão climática da cultura da cana de açúcar (Saccharum spp) para o estado da Paraíba. Revista Brasileira de Agricultura Irrigada, 10(3), 676-686.

INMET-Instituto Nacional De Meteorologia. (2019) Banco de dados meteorológicos para ensino e pesquisa. $B D M E P$.

Gonçalves, J. R. P., Moreira, A., Bull, L. T., Crusciol, C. A. C., \& Villas Boas, R. L. (2011). Granulometria e doses de calcário em diferentes sistemas de manejo. Acta Scientiarum. Agronomy, 33(2), 369-375. 
Research, Society and Development, v. 10, n. 7, e34710716784, 2021

(CC BY 4.0) | ISSN 2525-3409 | DOI: http://dx.doi.org/10.33448/rsd-v10i7.16784

Lima, C. G. R., de Passos, M., Souza, A., Costa, N. R., \& Montanari, R. (2016). Correlação entre componentes da produtividade da cana-de-açúcar com pH de um Argissolo vermelho distrófico do noroeste paulista. Revista Engenharia Na Agricultura-REVENG, 24(2), 120-130.

Maltoni, K. L., Oliveira, N. F. de., Boni, T. S. ., Faria, G. A. ., \& Cassiolato, A. M. R. . (2020). Uso da carapaça do mexilhão-dourado como substituto do calcário, na correção do solo e no fornecimento de cálcio. Research, Society and Development, 9(11), e93291110396. https://doi.org/10.33448/rsd$\underline{\mathrm{v} 9 \mathrm{i} 11.10396}$

Mello Prado, R., Fernandes, F. M., \& Natale, W. (2001). Uso agrícola da escória de siderurgia no Brasil: estudos na cultura da cana-de-açúcar. Funep.

Meneguetti CC, Mezaroba S, Groff AM (2010) Fatores relacionados ao cultivo da cana-de-açúcar. http://atividaderural.com.br/artigos/56019d9740759.pdf. Acessado em 13 de dezembro de 2019

Oliveira, E. C., Oliveira, R. I. D., de Andrade, B. M., Freire, F. J., Lira Júnior, M. A., \& Machado, P. R. (2010). Crescimento e acúmulo de matéria seca em variedades de cana-de-açúcar cultivadas sob irrigação plena. Revista Brasileira de Engenharia Agrícola e Ambiental, 14(9), 951-960.

Oliveira, C. M., Passos, R. R., Andrade, F. V., Dos Reis, E. F., Sturm, G. M., \& De Souza, R. B. (2010). Corretivos da acidez do solo e níveis de umidade no desenvolvimento da cana-de-açúcar. Revista Brasileira de Ciências Agrárias, 5(1), 25-31.

Peel, M. C., Finlayson, B. L., \& McMahon, T. A. (2007). Updated world map of the Köppen-Geiger climate classification. Hydrology and earth system sciences, 11(5), 1633-1644.

Ribeiro, J. E. D. S., Barbosa, A. J. S., Lopes, S. D. F., Pereira, W. E., \& Albuquerque, M. B. D. (2018). Seasonal variation in gas exchange by plants of Erythroxylum simonis Plowman. Acta Botanica Brasilica, 32 (2).

RIDESA. (2010) Catálogo nacional de variedades “RB” de cana-de-acúcar. 140.

Rosa, A., Caponi, L. H., \& Júnior, L. A. Z. (2016). Disponibilidade de fósforo em um Latossolo Vermelho em função do pH do solo. Acta Iguazu, 5(5), 108115.

Souza Ferraz, R. L., de Andrade Barbosa, M., LimaBatista, J., Dourado Magalhães, I., de Figueiredo Dantas, G., \& Oliveira Franco, F. (2015). Calagem em cana-de-açúcar: efeitos no solo, planta e reflexos na produção. InterfacEHS, 10(1), 166-177.

Vieceli, T. H. A., Maia, G. M., \& Conte, A. M. (2020). Gessagem e calagem determinando parâmetros fitométricos, qualidade tecnológica e produtividade da cana-de-açúcar. Revista Cultivando o Saber, 13(1), 58-70. 